\title{
A INTELIGÊNCIA EMOCIONAL NAS PRÁTICAS EDUCATIVAS: UMA ABORDAGEM SOBRE EDUCAÇÃO EMOCIONAL E SUA CONTRIBUIÇÃO PARA O DESENVOLVIMENTO INTEGRAL DO ALUNO
}

\author{
MATHEUS FIRMINO SAGITÁRIO* \\ PATRÍCIA MARGARIDA FARIAS COELHO $* *$
}

\begin{abstract}
RESUMO
A partir da implementação da BNCC em 2018, temos a presença da inteligência emocional no contexto da educação brasileira. Neste estudo consideramos, como hipótese, que o desenvolvimento da Inteligência Emocional auxilia os alunos e potencializa suas relações consigo e com o outro no mundo. Temos três objetivos, a saber: (i) apresentar o que é a inteligência emocional, (ii) verificar a importância da prática da Educação Emocional no desenvolvimento do aluno conforme as competências socioemocionais explicitadas na BNCC e (iii) discutir a implicação da Educação Emocional na prática. O que justifica essa escolha é o fato de que lidamos com inúmeros desafios e conflitos nas escolas, situações estas que ocorrem em sua maioria por falta de gerenciamento das emoções. O arcabouço teórico que sustenta este trabalho são os estudos de Pimenta (1997), de Bisquerra (2009) e de Goleman (2012) . A metodologia desse trabalho corresponde à bibliográfica, conforme aponta Gil (2002). O resultado alcançado nesta
\end{abstract}

* É graduado em Pedagogia pela Universidade Metodista de São Paulo (2020). Fez a pesquisa como Trabalho de Conclusão de Curso. Atualmente cursa especialização em psicopedagogia na modalidade pós-graduação lato sensu. E-mail: matheussagitario@hotmail.com

** É Doutora em Comunicação e Semiótica pela Pontifícia Universidade Católica de São Paulo e professora titular no PPGE da Universidade Metodista de São Paulo e coordenadora e professora do Mestrado em Ciências Humanas da Universidade Santo Amaro (UNISA). Foi orientadora da pesquisa para o artigo. E-mail: patriciafariascoelho@gmail.com 
pesquisa foi o entendimento sobre a importância Inteligência Emocional e sua aplicação na educação, na formação de professores e nas práticas em sala de aula. Dessa forma evidenciamos que as competências socioemocionais, como apresentadas na BNCC, compreendem as mudanças do mundo contemporâneo e contextualizam com a realidade e as necessidades atuais dos alunos, visando o desenvolvimento integral do sujeito.

Palavras chave: educação, emocional, práticas.

\begin{abstract}
Since the implementation of the BNCC in 2018, we have the presence of emotional intelligence in the context of Brazilian education. In this study, we consider, as a hypothesis, that the development of Emotional Intelligence helps students and enhances their relationships with themselves and with others in the world. We have three objectives, namely: (i) to present what emotional intelligence is (ii) to verify the importance of the practice of Emotional Education in the development of the student according to the social and emotional competencies explained in the BNCC, and (iii) discuss the implication of Emotional Education in practice. What justifies this choice is the fact that we deal with numerous challenges and conflicts in schools, situations that occur mostly due to lack of emotion management. The theoretical framework that supports this work is Pimenta (1997), Bisquerra (2009), and Goleman (2012). The methodology of this work will be bibliographic, as pointed out by Gil (2002). The results achieved were the understanding of the importance of Emotional Intelligence and its application to education, teacher training, and classroom practices. Thus, it is evident that social and emotional skills, as presented in the BNCC, understand the changes in the contemporary world and contextualize with the reality and the current needs of students, aiming at the integral development of the subject.
\end{abstract}

Key-words: education, emotional, practices. 


\section{INTRODUÇÃO}

$O$ ensino atual tem enfrentado muitos desafios frente às mudanças que ocorrem na sociedade, os conflitos de relacionamento têm invadido a sala de aula, a ponto de os educadores não saberem como lidar e resolvê-los. Os estudos apontam que por trás de tudo isso estão as emoções, as quais influenciam nossos comportamentos e tomadas de decisões.

Desta forma, neste estudo, apresentamos a prática da Inteligência Emocional como um caminho para a resolução desses conflitos, os quais envolvem as relações interpessoais dentro da escola, e, não somente isso, mas também como forma de melhorar o desempenho acadêmico dos alunos, pois a educação tradicional tem apenas valorizado o aspecto cognitivo, não visando o campo das emoções.

Bisquerra (2009) destaca que os aspectos emocionais são responsáveis por gerir nossos comportamentos. Assim sendo, nesta pesquisa apresentamos a prática da Inteligência Emocional como um caminho para resolução de conflitos internos, que envolvem as relações interpessoais dentro da escola, e, que também auxiliam a melhorar o desempenho acadêmico dos alunos.

É na escola que o aluno pode ter um melhor desempenho no rendimento acadêmico, pois há uma relação entre as emoções e o raciocínio cognitivo, que influenciam o aprendizado da criança. Por conseguinte, temos o interesse de compreender os estudos no campo da inteligência emocional que contribuem para a construção de uma Educação Emocional e seus aspectos, a partir da perspectiva da Base Nacional Comum Curricular.

A Base Nacional Comum Curricular (2021) é um documento nacional desenvolvido a partir da Lei de Diretrizes e Bases da Educação, com a finalidade de nortear os currículos e as propostas pedagógicas de todas as escolas do Brasil. Neste documento, além de apresentar os conteúdos que deverão ser ensinados, assim como o desenvolvimento de competências e habilidades, apresentam-se os aspectos da Inteligência Emo- 
cional a serem trabalhados em sala de aula, na forma de cinco competências socioemocionais, que são: 1 - Autoconsciência, 2 - Autogestão, 3 - Consciência social, 4 - Habilidades de relacionamento, 5 - Tomada de decisão responsável; visando a proteção à saúde mental e ao bullying e devendo ser o foco das propostas curriculares.

Em um artigo publicado em 2006, Severino nos apresenta a ideia de que educação não é apenas um processo institucional e instrucional, mas um investimento formativo do humano, tanto nas relações pedagógicas quanto social e coletiva, ou seja, não podemos pensar quando falamos em educação, como um instrumento que se resume a regras, instruções ou um grupo organizacional social, mas que num sentido amplo da concepção e prática, ela seja formativa. A partir da afirmação do pesquisador (2006) podemos refletir sobre as emoções em sala de aula como parte do desenvolvimento integral do ser humano e, assim, a educação cumprirá seu papel formativo. Se a educação é o caminho por onde passa a construção do ser, então é nela que o indivíduo pode estabelecer conexão com as emoções e explicitar como vê e sente o mundo.

A hipótese que sustenta essa pesquisa é que o desenvolvimento da inteligência emocional dos alunos se estabelece por meio das práticas educativas, que tenham por objetivos as competências emocionais que potencializem e melhorem suas relações consigo e com as pessoas, além de prepará-los para encarar os desafios que surgirem e para a vida.

$\mathrm{O}$ que justifica a escolha deste tema é reconhecermos a importância de tratarmos sobre as questões emocionais no ambiente educativo como uma forma de direcionar os discentes a uma compreensão de suas emoções. Como arcabouço teórico ancoramo-nos nos trabalhos desenvolvidos principalmente por, Selma Pimenta (1997), Rafael Bisquerra (2009), e Daniel Goleman (2012) dentre outros. 
Apresentados nossos objetivos, justificativa, hipótese, arcabouço teórico e uma breve contextualização do tema daremos continuidade com nosso estudo destacando a metodologia utilizada.

\section{METODOLOGIA}

Este trabalho constitui uma pesquisa bibliográfica ancorada em livros e artigos acadêmicos resultados de investigações acerca dos temas (i) Inteligência Emocional e (ii) Formação de Professores, além de nos fundamentarmos também em textos de autores que falam acerca do uso das habilidades dessa inteligência aplicada a, para e na educação em sala de aula. Foi necessário um levantamento de material textual bem específico que pudessem trazer o conhecimento para as reflexões propostas nesse instrumento e assim articular com as ideias que surgem a respeito do tema desenvolvido. Dessa forma, iremos discursar conforme as pesquisas realizadas e assim construir pontes de ideias e possiblidades que nos façam ampliar nossa visão para ações e práticas pedagógicas que contemplem um aprimoramento da prática docente, assim como o ensino das emoções para o desenvolvimento do aluno.

\section{O QUE É A INTELIGÊNCIA EMOCIONAL DE ACORDO COM BISQUERRA E GOLEMAN}

Em seu livro Psicopedagogia de las emociones, publicado por Bisquerra em 2009, temos a definição de Inteligência Emocional como "a habilidade de manejar os sentimentos e emoções, discriminar entre eles e utilizar estes conhecimentos para dirigir os próprios pensamentos e ações” (BISQUERRA, 2009, p. 128). Este conceito definido pelo professor Rafael Bisquerra (2009) está de acordo com as pesquisas de Mayer e Salovey (1997), os quais apontam que:

A inteligência emocional inclui a habilidade para perceber com precisão, atribuir valor e expressar sua emoção; a ha- 
bilidade de acessar e ou gerar sentimentos quando facilitam pensamentos; a habilidade de compreender as emoções e o conhecimento emocional; e a habilidade para regular as emoções para promover crescimento emocional e intelectual. (MAYER e SALOVEY, 1997, p. 10 apud BISQUERRA, 2009, p. 128)

De acordo com a natureza das emoções apresentada por Bisquerra (2009), o conceito de emoção é compreendido por um estado complexo do organismo. Fundamentados nas ideias do autor, temos o seguinte conceito:

Emoção é um estado complexo do organismo caraterizado por uma excitação ou perturbação que predispõe a ação (BISQUERRA, 2000). As emoções são geradas como resposta a um acontecimento externo ou interno. Um mesmo objeto pode gerar emoções diferentes em pessoas distintas. (BISQUERRA, 2009, p. 20)

Nesse ponto, o autor nos mostra serem as emoções respostas para acontecimentos internos ou externos, que nos provocam impulsos e nos movem para uma ação. Esta definição conversa com os pensamentos de Goleman (2012), o qual aponta as emoções como impulsos que levam a uma ação imediata, diante de situações que disparam nosso mecanismo emocional. Além disso, as emoções exercem um papel de influência muito importante para o pensamento, de forma a guiarem nossas decisões em todo momento. Contudo, são administradas pela nossa mente racional, e, quando fogem ao controle, o emocional "toma conta" como veremos na citação a seguir:

$\mathrm{Na}$ dança entre sentimento e pensamento, a faculdade emocional guia nossas decisões a cada momento, trabalhando de mãos dadas com a mente racional e capacitando - ou incapacitando - o próprio pensamento. Do mesmo modo, o 
cérebro pensante desempenha uma função de administrador de nossas emoções - a não ser naqueles momentos em que elas lhe escapam ao controle e o cérebro emocional corre solto. (GOLEMAN, 2012, p.53)

Dessa forma, é relevante explicar a diferença entre emoção e sentimento, que comumente são usados pelas pessoas para querer dizer a respeito da forma como nos expressamos emocionalmente. Para o neurologista Antônio Damásio, sentimentos e emoções tem definição e conceitos diferentes do ponto de vista da neurologia. Em sua obra O erro de Descartes (1994), o autor nos explica, em termos científicos, o esclarecimento sobre o que diferencia ambas as palavras, e, portanto, afirma:

O que é um sentimento? O que me leva a não usar indistintamente os termos "emoção" e "sentimento"? Uma das razões é que, apesar de alguns sentimentos estarem relacionados com as emoções, existem muitos que não estão: todas as emoções originam sentimentos, se se estiver desperto e atento, mas nem todos os sentimentos provêm de emoções. (DAMÁSIO, 1994, p. 135)

Ainda segundo o autor, enquanto as emoções são um "processo de avaliação mental e respostas dispositivos desse processo, resultado em um estado emocional” (DAMÁSIO, 1994, p.156), os sentimentos são a "percepção de todas as mudanças que constituem as respostas emocionais" (DAMÁSIO, 1994, p.156), sendo assim, os sentimentos são a experiência dessas mudanças.

Esse modelo de Inteligência Emocional que destacamos neste trabalho foi o publicado por Daniel Goleman no ano de 1995. O modelo, com base na teoria de Mayer e Salovey (1990), consiste em todas as diretrizes da inteligência emocional na forma de domínios principais a serem desenvolvidos pelo indivíduo. Vejamos cada um a seguir: 
1. Conhecer as próprias emoções: reconhecer os sentimentos quando acontecerem. Neste ponto, deve-se adquirir a capacidade de controlar os sentimentos, pois uma pessoa incapaz de observar os próprios sentimentos pode ser dominada por eles.

2. Lidar com as emoções: capacidade de reconfortar-se, livrar-se de emoções negativas que incapacitam e das consequências da falta dessa aptidão.

3. Motivar-se: a capacidade de se auto motivar e utilizar as emoções para empenhar-se em alguma atividade para realizá-la de forma satisfatória. Aqui se exerce o autocontrole emocional e domínio da impulsividade para alcançar objetivos.

4. Reconhecer as emoções dos outros: este elemento consiste na empatia, a aptidão base para o altruísmo. As pessoas consideradas empáticas são bons profissionais em trabalhos que vão lidar com pessoas diretamente, como assistencialismo e ensino, entre outros, pois tem a habilidade de entender o que os outros precisam e querem.

5. Lidar com os relacionamentos: é a habilidade de lidar com as emoções dos outros. As pessoas que desenvolvem essa aptidão se dão bem em qualquer situação na qual houver interação com as demais pessoas ao seu redor.

Para Goleman (2012), nossa capacidade de uso do intelecto só é possível com a parceria da nossa aptidão emocional e, com apoio nesse pensamento, entendemos a importância do desenvolvimento da Inteligência Emocional do indivíduo e nos propormos, então, a estudar a aplicação dela na área educacional, com o objetivo de os alunos aprenderem a lidar com suas emoções e poderem usar as habilidades dessa inteligência para resolução de conflitos, melhor desempenho acadêmico e na vida, visando saúde mental e bem-estar. 
Pesquisadores como Salovey e Mayer (1997 apud Bisquerra, 2009), Damásio (1994) e mesmo o escritor e pesquisador teórico, Daniel Goleman (1995), todos citados nessa pesquisa, tem nos mostrado a importância das emoções na vida humana e como nos relacionamos com elas. Entendemos que elas fazem parte da nossa natureza, assim como o aspecto cognitivo, classificando nossa espécie como pensante, por isso não podem ser desconsideradas dos estudos sobre o homem.

Compreendemos que os estudos sobre as emoções rompem com uma tradição de investigações das partes cognitivas e racionais supervalorizados aos longos dos anos, e exploram um campo até então desconhecido, mas relevante à espécie humana, o campo da mente emocional e suas emoções, que estão presentes em todos os momentos da vida, influenciando sobre nossos pensamentos, e também, sobre nossas decisões e ações.

Neste tópico apresentamos o que é Inteligência Emocional e suas características desvelando a importância deste estudo e de sua aplicação na área educacional com o intuito de auxiliar os alunos no desenvolvimento e compreensão de seus sentimentos e emoções. Abordaremos, a seguir.

\section{A IMPORTÂNCIA DA PRÁTICA DA EDUCAÇÃO EMOCIONAL}

A concepção proposta neste trabalho é que a educação tem por finalidade o desenvolvimento do ser humano, bem como prepará-lo para a vida, segundo Bisquerra (2005). Para o autor (2009), durante muito tempo a educação tem visado apenas os aspectos cognitivos que vemos representada pelo conteúdo do conhecimento humano nos currículos escolares como: linguagem, matemática, geografia, dentre outras, enquanto os outros aspectos, como o emocional, têm estado ausentas das práticas educativas na escola. Sobre isso ele afirma: 
Se há concentrado basicamente na instrução cognitiva (aquisição de conhecimentos em linguagem, matemática, ciências sociais, naturais, arte, educação física etc.). mas muitos aspectos relacionados com as inteligências múltiplas, a inteligência emocional e as competências emocionais têm estado, de modo geral, ausente da prática educativa. (BISQUERRA, 2009, p. 158)

Dessa maneira, evidenciamos que Educação Emocional surgiu a partir dos estudos da Inteligência Emocional, para atender as necessidades sociais que as matérias acadêmicas não suprem, conforme explica Bisquerra (2009). O autor a caracteriza como uma inovação educativa, isso porque ela nos permite refletir sobre a importância de promover práticas educativas que contemplem o desenvolvimento integral dos alunos, no contexto de um mundo em plena transformação e revolução tecnológica. Para Bisquerra (2005), o conceito de Educação Emocional é o desenvolvimento das competências emocionais para a ampliação integral do ser humano e capacitação para a vida, visando bem-estar pessoal e social. Dessa forma:

Concebemos a educação emocional como um processo educativo, contínuo e permanente, que pretende potenciar o desenvolvimento das competências emocionais, como elemento essencial do desenvolvimento integral da pessoa, com o objetivo de capacitar para a vida. Ela tem por finalidade aumentar o bem-estar pessoal e social. (BISQUERRA, 2005, p. 96)

Com base na teoria da Inteligência Emocional e na concepção de uma educação que tem por finalidade preparar a pessoa, no caso o aluno, para a vida, difere de uma postura tradicional escolar do século XX, que perdura até os dias atuais, visando somente os conteúdos do conhecimento humano e 
desconsiderando o fator emocional. Entretanto, na atualidade, principalmente a partir de 2015, a escola começa a olhar para os aspectos emocionais e isso nos permite refletir e compreender o quanto trabalhar a dimensão emocional é importante se visamos o desenvolvimento integral dos alunos.

Recentemente, o Brasil tem implementado a sua Base Nacional Comum Curricular (BNCC, 2021), um documento que reúne todas as aprendizagens essenciais para todas as etapas da educação básica no país. Segundo a BNCC:

A base nacional comum curricular é um documento normativo que define o conjunto de aprendizagens essenciais que todos os alunos devem desenvolver ao longo das etapas e modalidades de Educação Básica. (BNCC, 2021)

Uma das novidades deste documento é a inserção de cinco competências socioemocionais a serem desenvolvidas na educação, com base nos estudos das emoções. Segundo orientação da BNCC (2021), estas competências devem estar inseridas no currículo escolar, o que contempla as ideias e propostas supracitadas por Bisquerra (2009). A BNCC destaca ainda, como essenciais, o fator de proteção da saúde mental e a compreensão do que é o bullying $e$ os efeitos causados por ele no ambiente escolar.

Evidenciamos que as competências trazidas na BNCC (2021) apresentam similaridades com as propostas por Bisquerra (2009), pois a BNCC tem como referência o CASEL, uma organização que leva o ensino socioemocional às escolas em todo o mundo (GOLEMAN, 2012) e baseia-se nas pesquisas sobre Inteligência Emocional. As competências socioemocionais da BNCC (2021) são: • Autoconsciência • Autogestão; • Consciência social; $\bullet$ Habilidade de relacionamento; $\bullet$ Tomada de decisão responsável.

A BNCC (2021) nos indica a contextualização, a realidade e as transformações que vêm acontecendo com o homem, seu 
modo de agir e pensar no século XXI. Destacamos a inserção das competências socioemocionais na BNCC e, por conseguinte, nos currículos escolares; consideramos uma inovação na educação no Brasil em comparação a outros países como Estado Unidos e seus programas de educação socioemocional trabalhados desde a década de noventa.

No Brasil, inserindo o ensino das emoções na escola, destacamos a crescente importância da concepção de educação que se empenha para o desenvolvimento integral do aluno. Nesse novo contexto, com as questões socioemocionais sendo desenvolvidas no ambiente educacional, as escolas têm se modificado e procurado se atualizar em suas práticas e metodologias de educar, bem como em seu próprio currículo. Evidenciamos que isso nos mostra uma tendência a rever a finalidade e os propósitos da educação na atualidade.

Corroboramos que a ação de inserir conteúdo emocional traz inovação a educação e permite, ainda, abrir novos caminhos, não somente para refletir, mas também para fazer uma educação diferente, atendendo as necessidades do indivíduo no contexto do mundo atual. Ao inserir as competências socioemocionais nos currículos escolares, por meio da BNCC (2021), observamos a importância de construir um currículo que contextualize com a realidade dos educandos e atenda às demandas do mundo contemporâneo, pois:

A função das instituições de ensino está além da construção do conhecimento, elas necessitam fortalecer diversas competências nos educandos, para que lhes possibilitem construir uma vida produtiva e feliz em uma sociedade marcada pela velocidade das mudanças (SCHAEFER, 2018, p. 30)

Em um artigo publicado por Vitor da Fonseca (2016), professor da Universidade de Lisboa, o autor discorre sobre como funciona a relação das emoções com o cognitivo, quando se está aprendendo. Segundo o autor (2016, p. 317): 
As emoções afetam todas as aprendizagens, quanto mais envolvidas forem com elas, mais mobilizadas são as funções cognitivas da atenção, da percepção e da memória, e bem mais geridas e fortes serão as funções executivas de planificação, priorização e verificação de respostas.

Dessa forma, conforme verificamos apoiados em Fonseca, as emoções auxiliam na aprendizagem, pois Inteligência Emocional em cotejo com as emoções exercem um papel muito importante sobre nosso racional, de forma que elas podem implicar em nossas decisões e comportamentos, assim como a respeito das funções cognitivas, afeta a assimilação de conteúdo. Constatamos, assim, que não podemos desconsiderar a importância das emoções no processo de ensino e aprendizagem e da vida escolar, visto que elas mobilizam uma série de funções cognitivas importantes para a aprendizagem. Ressaltamos não saber se Fonseca (2016) teve contato com as teorias da Inteligência Emocional, mas ele entende a necessidade de uma educação no século XXI que aborde as emoções no ensino, como veremos a seguir:

As emoções não podem continuar a ser separadas das cognições nas escolas e nas salas de aula. Do século XXI, como foram no passado, a aprendizagem significativa e motivadora é o resultado da interação entre a emoção e a cognição, ambas estão conectas a um nível neuro funcional tão básico, que se uma não funcionar a outra é afetada consideravelmente. (FONSECA, 2016, p. 371)

Anita Abed (2016) é outra pesquisadora que, assim como Fonseca (2016), reconhece a importância das questões socioemocionais e do papel da escola na formação dos alunos, uma vez que:

A função da escola vai muito além da transmissão do conhecimento, pois é urgente e necessário fortalecer muitas 
e variadas competências nas nossas crianças e jovens, que lhe possibilitem construir uma vida produtiva e feliz em uma sociedade marcada pela velocidade das mudanças. Motivação, perseverança, capacidade de trabalhar em equipe e resiliência diante de situações difíceis são algumas das habilidades socioemocionais imprescindíveis na contemporaneidade... E no futuro dos nossos alunos. (ABED, 2016, p.14)

A autora nos faz entender a importância das emoções na aprendizagem e a Educação Emocional como parte do ensino escolar. Consideremos as práticas educativas que trabalham o desenvolvimento das competências emocionais como parte importante e essencial no processo de formação e desenvolvimento integral do aluno.

Nesse subtítulo apresentamos as pesquisas de Bisquerra em coteja com as propostas da BNCC no qual ambos destacam, cada um a sua maneira, a importância de se trabalhar as questões socioemocionais na escola.

\section{A IMPLICAÇÃO DA EDUCAÇÃO EMOCIONAL NA PRÁTICA EDUCATIVA: FORMAÇÃO DE PROFESSORES E PRÁTICA EM SALA DE AULA}

O ensino das emoções em sala de aula não é novidade. Daniel Goleman, desde 1995 já explicitava a importância de se trabalhar as emoções no ambiente educacional, como se pode verificar em seu prefácio à edição brasileira, na qual o pesquisador deixa a seguinte orientação aos docentes:

Aos professores, sugiro que considerem também a possibilidade de ensinar as crianças o alfabeto emocional, aptidão básica do coração. Tal como hoje ocorre nos estados unidos, o ensino brasileiro poderá se beneficiar com a introdução, no currículo escolar, de uma programação de 
aprendizagem que, além de disciplinas tradicionais, inclua ensinamentos para uma aptidão pessoal fundamental - a alfabetização emocional. (GOLEMAN, 2012, p.19)

Para trabalhar as competências emocionais na escola, a Educação Emocional requer uma formação prévia dos professores, pois conforme professor Bisquerra (2009), o desenvolvimento de competências emocionais de forma intencional e sistemática, está ausente dos programas de formação de professores.

Essa ausência pode nos acarretar uma problemática em relação à necessidade de formar professores frente à demanda dos conteúdos da Educação Emocional. Ao refletirmos sobre a formação docente, apontamos dois aspectos importantes para esse processo formativo. Estes aspectos são apresentados pela autora Selma Garrido Pimenta (1997), sendo eles: $1^{\circ}$ - colaboração na construção da identidade do professor e $2^{\circ}$ - os saberes da docência.

No primeiro aspecto, Pimenta (1997), discursa sobre a formação inicial dos professores e sua responsabilidade na preparação dos futuros professores e sua construção enquanto docente. A autora apresenta uma proposta de formação em que o professor possa, a partir dela, criar uma consciência sobre sua prática e, assim, transformar seus modos de saber fazer num processo contínuo de construção de sua identidade. Já no segundo aspecto, entendemos que o ponto de foco são os saberes docentes oriundos da experiência como parte desse processo formativo que compreende não somente os estudos teóricos, mas a observação das próprias práticas.

Neste momento inicial em que as escolas começam a se preparar para trabalhar as competências socioemocionais, pensamos que o professorado e toda equipe escolar podem considerar sua inexperiência neste novo campo de domínio, para que a partir das práticas que irão exercer, possam ir aprimorando seus modos de saber-fazer em sala de aula, considerando o que 
Pimenta (1997) propõe sobre a formação de professores. Desse modo Pimenta (1997, p. 12) afirma:

Nesse sentido, a formação envolve um duplo processo: o de auto formação dos professores, a partir da reelaboração constante dos saberes que realizam em sua prática, confrontando suas experiências nos contextos escolares; e o de formação nas instituições escolares onde atuam.

Ao apresentar uma formação composta por uma autoformação, além da formação nas instituições escolares como já sabemos, percebemos a presença de um professor que tem a habilidade de, como diz a autora, confrontar suas próprias experiências, e dessa forma, é possível a reelaboração constante dos saberes de sua prática docente. Acreditamos que essa característica seja fundamental para esse professor que vai trabalhar os aspectos emocionais, ao rever suas próprias práticas em relação às experiências que o ensino das emoções pode promover.

Com base nos estudos do professor Bisquerra (2009), ressaltamos que o ideal em relação à formação de professores em Educação Emocional seria começar em sua formação universitária para que esteja apto a ensinar os conteúdos referente aos estudos e práticas acerca das emoções e competências emocionais, visto que, conforme a BNCC, este conteúdo estará presente nos currículos escolares. Com isso, pensamos que as universidades contribuirão com a atualização das práticas docentes se acompanharem as mudanças que estão acontecendo na educação com a proposta da BNCC. Para isso seria necessário uma reformulação da grade curricular para disponibilizar uma disciplina ou duas que atendam às questões socioemocionais conforme propostas por Goleman (2012).

Daniel Goleman (2012) critica a formação padrão dos professores que não os preparam para ensinar as emoções, e até aqui nos faz deduzir que ensinar as crianças sobre as emoções 
no formato de uma Educação Emocional, inserida num currículo escolar, requer que este educador esteja não somente preparado, mas tenha domínio das suas próprias emoções e, também, seja capaz de exercer as competências emocionais para que seja e sirva como exemplo a seus alunos.

Assim sendo, segundo Goleman (2012), é normal que os cursos de alfabetização emocional forneçam aos professores semanas de treinamento especial na técnica. Sobre a reação dos professores ao ensino das emoções, o autor faz a seguinte observação:

Os professores podem relutar em dedicar mais uma parte do dia escolar a assuntos que parecem não estar relacionados com o básico acadêmico, alguns professores podem sentir-se muito pouco à vontade para ensinar esse tipo de matéria e todos precisarão de treinamento especial para fazê-lo. (GOLEMAN, 2012, p. 296)

Concluímos, portanto, que a proposta de uma concepção de formação que explora não somente o campo dos saberes, mas que observa e analisa o fazer, seja a adequada para alcançar o ensino das emoções na escola. Verificamos também que isso não apenas fortalece as práticas deste professor, como pode contribuir para o aperfeiçoamento da profissão. Sobre o assunto, Nóvoa aponta (1992, p. 15) que:

A formação passa pela experimentação, pela inovação, pelo ensaio de novos modos de trabalho pedagógico. E por uma reflexão crítica sobre a sua utilização. A formação passa por processos de investigação, diretamente articulados com as práticas educativas.

Nóvoa (1992) evidencia, assim, que as transformações no fazer pedagógico são importantes e ocorrem não só na formação inicial, mas também na formação continuada, apesar de não 
ser uma tarefa fácil diante de tantos desafios que aparecem ao longo da carreira docente e, ao mesmo tempo, não seja agradável ou fácil o processo de desconstrução para (re)construir, ou permitir se (re)fazer em novas práticas e técnicas. No entanto, presumimos que o primeiro passo é a experimentação dos novos saberes e fazeres para, a partir disso, os docentes verificarem as possibilidades, tentativas, erros e acertos, como parte desse processo de formação docente inicial e/ou continuada que discutimos. Neste tópico abordamos a implicação da Educação Emocional na prática docente evidenciando a importância de, desde a formação inicial e/ou continuada, os professores terem acesso ao conteúdo de educação emocional para facilitar sua prática no momento em que estiver atuando em sala de aula.

\section{CONSIDERAÇÕES FINAIS}

A Inteligência Emocional veio para nos conectar àquilo que nos torna mais humanos, portanto, essa pesquisa nos permitiu entender a sua importância em uma educação que tem por concepção a formação humana, e por finalidade preparar o sujeito para a vida. O ensino das competências emocionais vem sendo importante num contexto de um mundo em plena mudança e transformação dos conteúdos disponibilizados nos currículos escolares, na grade curricular da formação inicial dos professores e nas práticas docentes.

Todos os objetivos propostos neste estudo foram alcançados. O primeiro objetivo alcançado foi o de podermos entender o que é Inteligência emocional e quais suas características compreendendo sua importância para o desenvolvimento humano.

Já no segundo objetivo, comprovamos que a prática da Inteligência Emocional, por meios de um programa de Educação Emocional nas escolas, pode ajudar os alunos e potencializar suas relações, conforme desenvolvem as competências socioemocionais, como as descritas na BNCC (2021). Verificamos que a inserção das competências socioemocionais na BNCC (2021), é 
um passo importante para a educação brasileira da nossa época, ainda que tardio, de acordo com o surgimento das teorias das emoções que já são trabalhadas em outros países desde os anos 1990, como os Estado Unidos, por exemplo. Destacamos, ainda, o quanto é desafiador para professores e alunos, trabalharem as emoções em um ensino tradicional, que supervaloriza o cognitivo, mas segundo as propostas da BNCC (2021) deve ser alterado para um ensino mais humanizado e conectado às emoções.

No terceiro objetivo foi possível compreender as implicações da Educação Emocional sobre Inteligência Emocional quando posta em exercício e verificar que, quando aplicada à educação, exige de antemão uma formação de professores, seja na formação inicial e/ou formação continuada, para que estes estejam preparados a trabalhar as competências socioemocionais em sala de aula. Ressaltamos que a Inteligência Emocional aplicada às práticas educativas não vem como solução aos problemas educacionais, mas como proposta de um meio que pode auxiliar a encarar os desafios e encontrar as possíveis soluções.

Verificamos, ainda, a importância da Educação Emocional no processo de formação do aluno, entendendo como se comportam as emoções e sua influência sobre nossas decisões, comportamentos e aprendizagem, por meio dos estudos em Inteligência Emocional, assim também como sua contribuição para o desenvolvimento integral da criança, visando os aspectos cognitivos e emocionais como essenciais.

Nossa hipótese foi comprovada, pois foi possível confirmar, por meio da arguição dos pesquisadores que fizeram parte da fundamentação teórica dessa pesquisa, Pimenta (1997), de Bisquerra (2009) e de Goleman (2012), dentre outros, que o desenvolvimento da inteligência emocional auxilia na aprendizagem dos alunos, quando o professor (re)pensa suas práticas educativas, por meio de novas abordagens, as quais ocasionam a proposta do desenvolvimento das competências emocionais que potencializam as relações do aluno consigo mesmo e com as 
pessoas que o rodeiam, preparando-o para os desafios da vida.

Concluímos que durante séculos a escola tem visado somente o desenvolvimento da cognição no processo de ensino-aprendizagem, mas agora no século XXI, pesquisadores e professores têm se atentado ao fato de não poderem mais manter um tipo de proposta educacional arcaica. A escola passa por um momento de transformação, no qual as questões socioemocionais estão sendo valorizadas no ambiente educacional, e exigem novas práticas docentes, pois as matérias curriculares tradicionais não têm sido suficientes no preparo dos alunos para lidarem com os desafios do mundo contemporâneo.

Sabemos que ainda há muito para se pensar, propor, discutir e aprender sobre as questões socioemocionais e a BNCC (2021), que agora evidencia e exige uma mudança na prática dos professores. No entanto estamos sedentos por mudanças e transformações na escola, uma escola mais humana e mais sensível às questões da inteligência emocional.

\section{REFERÊNCIAS}

ABED, Anita Lilian Zuppo. O desenvolvimento das habilidades socioemocionais como caminho para a aprendizagem e o sucesso escolar de alunos da educação básica. Construção psicopedagógica. vol. 24 nº. 25, São Paulo, 2016. Disponível em: < http://pepsic.bvsalud.org/scielo.php?script=sci_artte xt\&pid=S141569542016000100002 > . Acesso em: 15 de nov. de 2020.

BISQUERRA, R. Psicopedagogia de las emociones. Espanha: Editorial Sintesis, 2009.

Educación emocional em la formación del professorado. Revista

Interuniversitaria de Formación del Profesorado, 19 de maio de 2005, 95-114 Disponível em: https://www.redalyc.org/pdf/274/27411927006.pdf. Acesso em: 18 de mar de 2020.

BRASIL. Ministério da Educação. Base Nacional Comum Curricular. Disponível em: < http://basenacionalcomum.mec.gov.br/images/BNCC_EI_ EF_110518_versaofinal_site.pdf > . Acesso em: 16 mai. 2021.

DAMÁSIO, A. R. O erro de Descartes: emoção, razão e cérebro humano. São Paulo: Companhia das Letras, 1994. 
FONSECA, Vitor da. Importância das emoções na aprendizagem: uma abordagem neuropsicopedagógica. Revista psicopedagógica. vol.33 no.102 São Paulo, 2016. Disponível em: < http://pepsic.bvsalud.org/scielo.php?script=sci_ arttext\&pid=S0103-84862016000300014 >. Acesso em: 16 de nov. de 2020.

GIL, Antonio Carlos. Como elaborar projetos de pesquisa. São Paulo. Atlas, 2002.

GOLEMAN, D. Inteligência emocional: a teoria revolucionária que redefine o que é ser inteligente. $2^{\circ}$ ed. Rio de janeiro: Objetiva,2012.

NÓVOA, Antônio. Formação de professores e profissão docente, 1992. Disponível em: <http://hdl.handle.net/10451/4758>. Acesso em: 15 de nov. de 2020.

PIMENTA, Selma Garrido. Formação de professores -saberes da docência e identidade do professor. Nuances-Vol. III- setembro de 1997. Disponível em: <https://edisciplinas.usp.br/pluginfile.php/1287224/mod_resource/ content $/ 1 /$ Pimenta_

Form $\% 20 \mathrm{de} \% 20$ profs $\% 20 \mathrm{e} \% 20$ saberes $\% 20 \mathrm{da} \% 20$ docencia.pdf $>$. Acesso em 15 de nov. 2020.

SCHAEFER, Jaqueline Grunewald. Bullying: um enfoque socioemocional através de um videoclipe. 2018. 81f. Trabalho de Conclusão de Curso - Universidade Federal do Rio Grande do Sul, Porto Alegre, 2018.

SEVERINO, Antônio Joaquim. A busca do sentido da formação humana: tarefa da Filosofia da Educação. Educação e Pesquisa. 2006, vol.32, n.3, p. 619-634. Disponível em: < https://www.scielo.br/scielo.php?pid=S1517970220 $06000300013 \&$ script $=$ sci_abstract $\&$ tlng $=$ pt $>$. Acesso em: 18 de mar de 2020. 